\title{
Influence of stiffness characteristics of a railway track on output parameters in a multibody model
}

\author{
Ján Dižo ${ }^{1, *}$, and Miroslav Blatnický ${ }^{1}$ \\ ${ }^{1}$ University of Žilina, Faculty of Mechanical Engineering, Department of Transport and Handling \\ Machines, Univerzitná 8215/1, 01026 Žilina, Slovak Republic
}

\begin{abstract}
The article is aimed at the research of the influence of stiffness characteristics included in a model of a railway track, which is the part of a multibody system. The other part of the multibody model is a railway vehicle. Authors are focused on the investigation of response of some selected output parameters under various values of input of stiffness and damping coefficients. The interaction of a railway vehicle and a railway track is studied. A passenger railway vehicle has been chosen for presented research. Outputs parameters are chosen in the passenger ride comfort point of view and the running safety point of view. The passenger ride comfort can be evaluated either by the direct method, when a real vehicle runs on a track and passengers evaluate a vehicle by means of their feelings during the ride or by means of the indirect method, when accelerometers are used for measuring accelerations in various positions of a tested wagon and subsequently values of accelerations are processed in required way. Then, the ride comfort is calculated and indexed by means of ride comfort indices. In the presented work, the indirect method has been used. In the computer multibody model of the wagon accelerations on a floor have been detected and the mean ride comfort for a person is assessed. The ride safety is most often determined by waveforms of vertical wheel forces, lateral wheel forces and the derailment quotient.
\end{abstract}

\section{Introduction}

A rail vehicle is a relatively complicated mechanical system. It is specified by its properties and together with a railway track form basic elements of railway transport system. In terms of mechanics, a railway vehicle is a multibody system, whose behaviour in relation to a railway track and surrounding environment is analysed and evaluated based on given criteria [1-4]. In process of design of railway vehicle, it is necessary to meet as far as possible the requirements and operating conditions, in particular with regard to running safety and level of passengers ride comfort [5,6]. Simulation calculations of railway vehicles running are focused on investigation of dynamics of a railway vehicle mechanical system, which is most often excited due to track irregularities [7-9].

\footnotetext{
*Corresponding author: jan.dizo@fstroj.uniza.sk
} 
The objective of the article is to analyse running properties of a railway vehicle by means of simulation computations in commercial simulation software. For these purposes, a passenger wagon model and a railway track model are created. The research examines, how the change of stiffness-damping parameters of the railway track influences dynamic properties of the passenger wagon. These dynamic properties are evaluated mainly from the passengers ride comfort point of view and from the running safety point of view.

\section{Description of an analysed multibody system}

A virtual model of the passenger car and the railway track has been created in the Simpack software package. In this software, a user can create various virtual multibody models from a simple wheelset to complicated high-speed trainsets, perform extensive dynamic simulations, animate movements of individual elements of an entire model etc. The Postprocessor interface offers extensive options of visualization of reached results by means of 2D or 3D graphs, animations as well as sophisticate mathematical operation with calculated data using implemented algorithms [1, 10-12]. They allow to compute and to evaluate passenger ride comfort, to assess the running safety etc.

\subsection{A railway vehicle model}

The multibody model of the analysed passenger wagon consists of two subsystems of bogies and one subsystem of the body of wagon (Fig. 1). Every subsystem includes several construction elements. The bogie model is formed by one frame, two wheelsets and four axleboxes. These elements are interconnected by means of force elements, joints and constraints. Coils springs and hydraulic dampers act in vertical direction between axleboxes and bogie frame (primary suspension system) as well as between bogie frame and the wagon body (secondary suspension system). The suspension system comprises also additional hydraulic dampers of yaw and lateral oscillations.
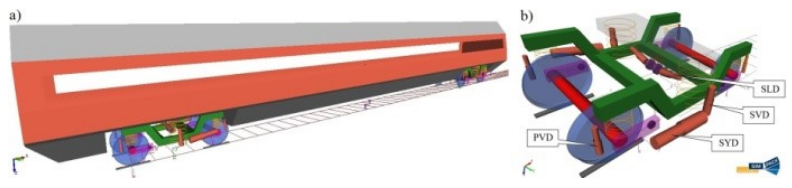

Fig. 1. A multibody model of a passenger wagon a) and a multibody model of a bogie b) created in the Simpack software: PVD - a primary vertical damper, SVD - a secondary vertical damper, SLD a secondary lateral damper, SYD - a secondary yaw damper.

\subsection{A railway track model}

Simulations of railway vehicle running are usually performed for a rigid track formulation. However, there are technical applications, in which there is necessary to take into account, that the track base is not rigid, but it is flexible [9, 13-15]. Such a model of a track is extended with additional bodies, kinematic and mechanical joints with defined stiffnessdamping parameters. It causes increasing of degrees of freedom. The scheme of the flexible track is shown in Fig. 2. Stiffness-damping characteristics are defined in principle in two ways: as constant values and as functional dependences on travelled distance. In our research we have used both ways.

Results of simulation computations are differentiated using characteristic words as following:

- Rigid track formulation - "Rigid", 
- Flexible track formulation with constant stiffness-damping parameters - "Flex_const"with following characteristics: total vertical track stiffness $k_{z}=1.65 \cdot 10^{8} \mathrm{~N} \cdot \mathrm{m}^{-1}$, total vertical track damping $b_{z}=1.90 \cdot 10^{5} \mathrm{~N} \cdot \mathrm{s} \cdot \mathrm{m}^{-1}$, total lateral track stiffness $k_{y}=4.15 \cdot 10^{7} \mathrm{~N} \cdot \mathrm{m}^{-1}$, total lateral track damping $b_{y}=1 \cdot 10^{5} \mathrm{~N} \cdot \mathrm{s} \cdot \mathrm{m}^{-1}$,

- Flexible track formulation with variable parameters - "Flex_sin". In this case, stiffnessdamping parameters are defined by sinusoidal functions, where track frequency of the sinusoidal function depends on travelled distance.

Simulation computations have been performed on a real track geometry including right and left curves with various diameters. Moreover, the track model contains track irregularities. The passenger wagon was running at the speed of $60 \mathrm{~km} \cdot \mathrm{h}^{-1}, 90 \mathrm{~km} \cdot \mathrm{h}^{-1}$ and $110 \mathrm{~km} \cdot \mathrm{h}^{-1}$.

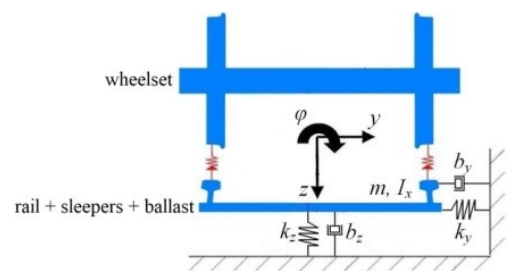

Fig. 2. A dynamical scheme of a flexible railway track.

\section{Results of simulation computations}

Results of dynamic analyses of tested passenger wagon with defined input parameters are introduced in this section.

As the main criteria, passenger ride comfort has been evaluated. It is represented by means of column graphs, which characterise the level passenger ride comfort in selected points. Passenger ride comfort is assessed based on distribution of the $N_{M V}$ indices, i. e. the average ride comfort on the wagon body floor $[5,16]$. For calculation of this index, there is necessary to know accelerations in each point [17-19]. The acceleration signal is processed using corresponding filters in compliance with the EN 12299:2009 standard [5, 17, 19].

Reached values of passenger ride comfort indices depending on various stiffnessdamping characteristics of the track and for various running speeds are shown in Fig. 3, Fig. 4 and Fig. 5.

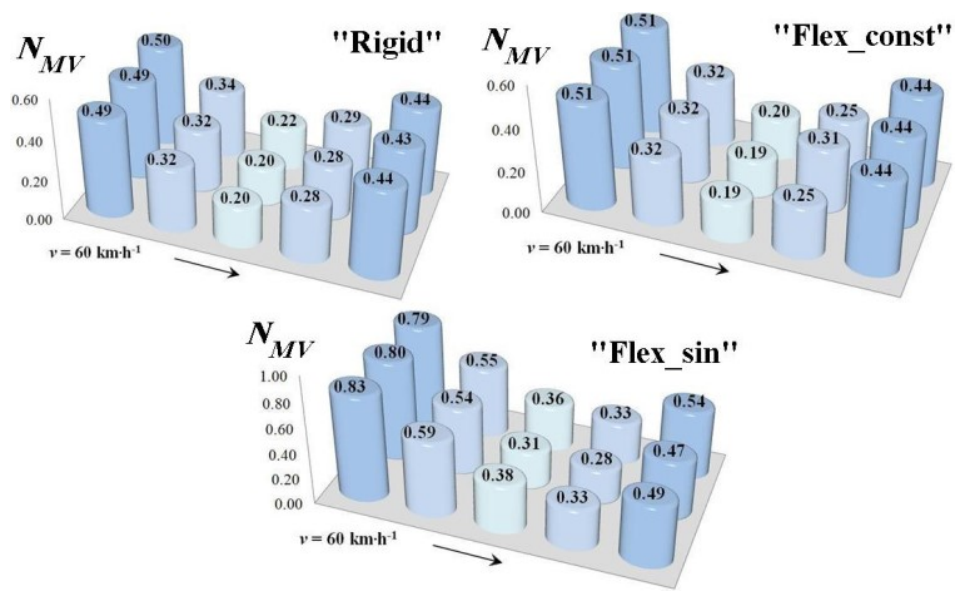

Fig. 3. Values of $N_{M V}$ index for "Rigid", "Flex_const" and "Flex_sin" formulation, speed of $60 \mathrm{~km} \cdot \mathrm{h}^{-1}$. 


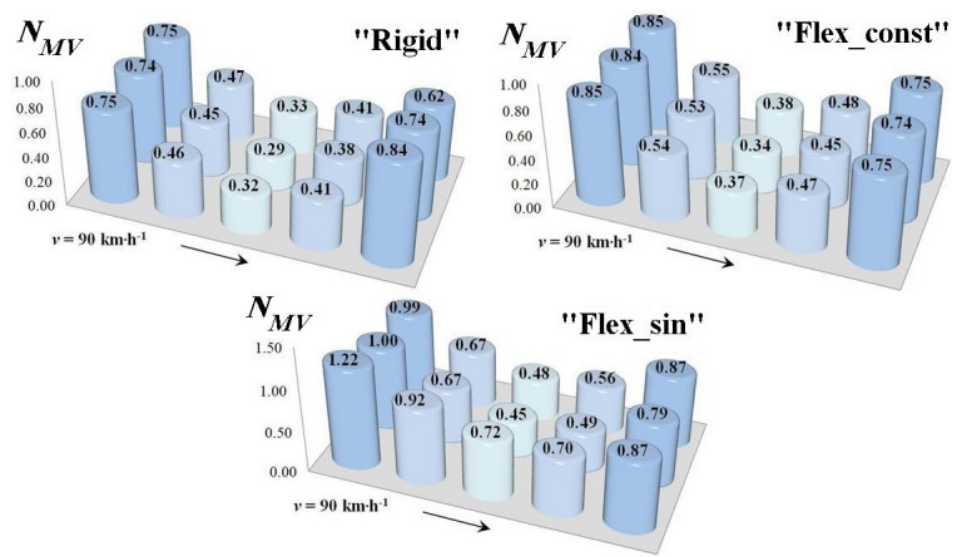

Fig. 4. Values of $N_{M V}$ index for "Rigid", "Flex_const" and "Flex_sin" formulation, speed of $90 \mathrm{~km} \cdot \mathrm{h}^{-1}$.

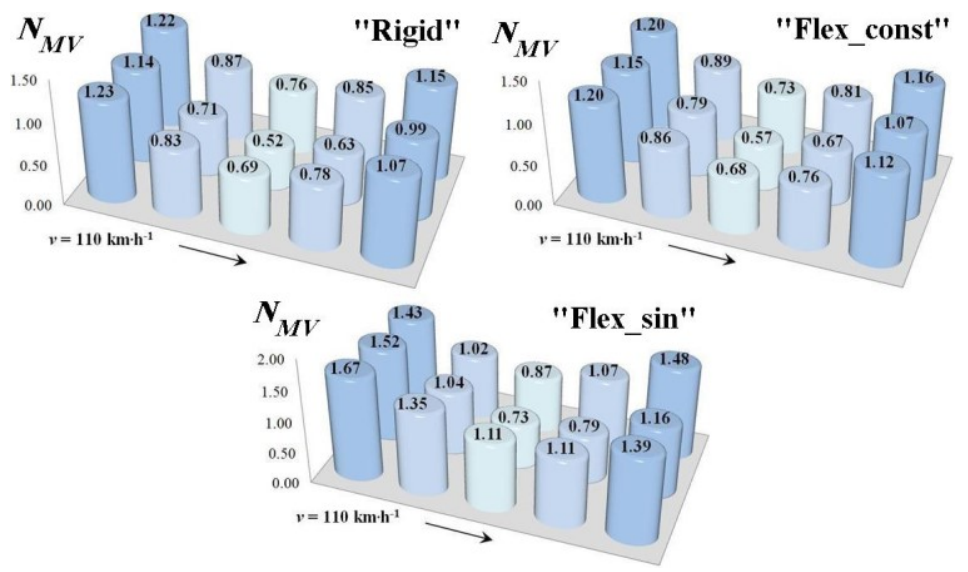

Fig. 5. Values of $N_{M V}$ index for "Rigid", "Flex_const" and "Flex_sin" formulation, speed of $110 \mathrm{~km} \cdot \mathrm{h}^{-1}$.

Values of ride comfort indices $N_{M V}$ obtained from simulation computations for the speed of $60 \mathrm{~km} \cdot \mathrm{h}^{-1}$ show (Fig. 3), that definition of constant values of stiffness-damping characteristics of the track ("Flex_const") only weakly affects the ride comfort in comparison with the rigid track formulation ("Rigid"). However, the flexibility of the track is determined by means of variable stiffness-damping characteristics ("Flex_sin"), values of ride comfort are greater. Therefore, the same passenger car is evaluated as less comfortable.

Graphs in Fig. 4 show the distribution of $N_{M V}$ indices for the speed of $90 \mathrm{~km} \cdot \mathrm{h}^{-1}$. We can see, that higher values of the speed cause greater values of $N_{M V}$ indices. Moreover, the formulation of the flexible track with constant values of stiffness-damping characteristics ("Flex_const") is more pronounced, while variable values of the flexible track formulation ("Flex_sin") again indicate the greatest values of $N_{M V}$ indices.

Finally, the case of the wagon running at the speed of $110 \mathrm{~km} \cdot \mathrm{h}^{-1}$ is evaluated (Fig. 5). As expected, the ride in the wagon at this speed is least comfortable. In more detailed examination in this case, the formulation of track flexibility with constant values of stiffness-damping characteristics ("Flex_const") leads in rear part of the wagon to lower values of $N_{M V}$ indices in comparison with the rigid track formulation ("Rigid"). However, deviations are negligible. The wagon is also in this case evaluated as very comfortable 
except of two points in rear part of the body, in which the wagon is evaluated as comfortable.

A railway vehicle is also assessed in term of running safety. One of the main evaluated quantities is the derailment quotient $Y / Q$, which is given as the ratio of the lateral wheel forces $Y$ and the vertical wheel forces $Q$.

Figure 6 shows waveforms of the derailment quotient for the speed of $60 \mathrm{~km} \cdot \mathrm{h}^{-1}$. Waveforms belongs to the first wheelset in the running direction, while blue curve is for the right wheel and the green curve is for the left wheel.

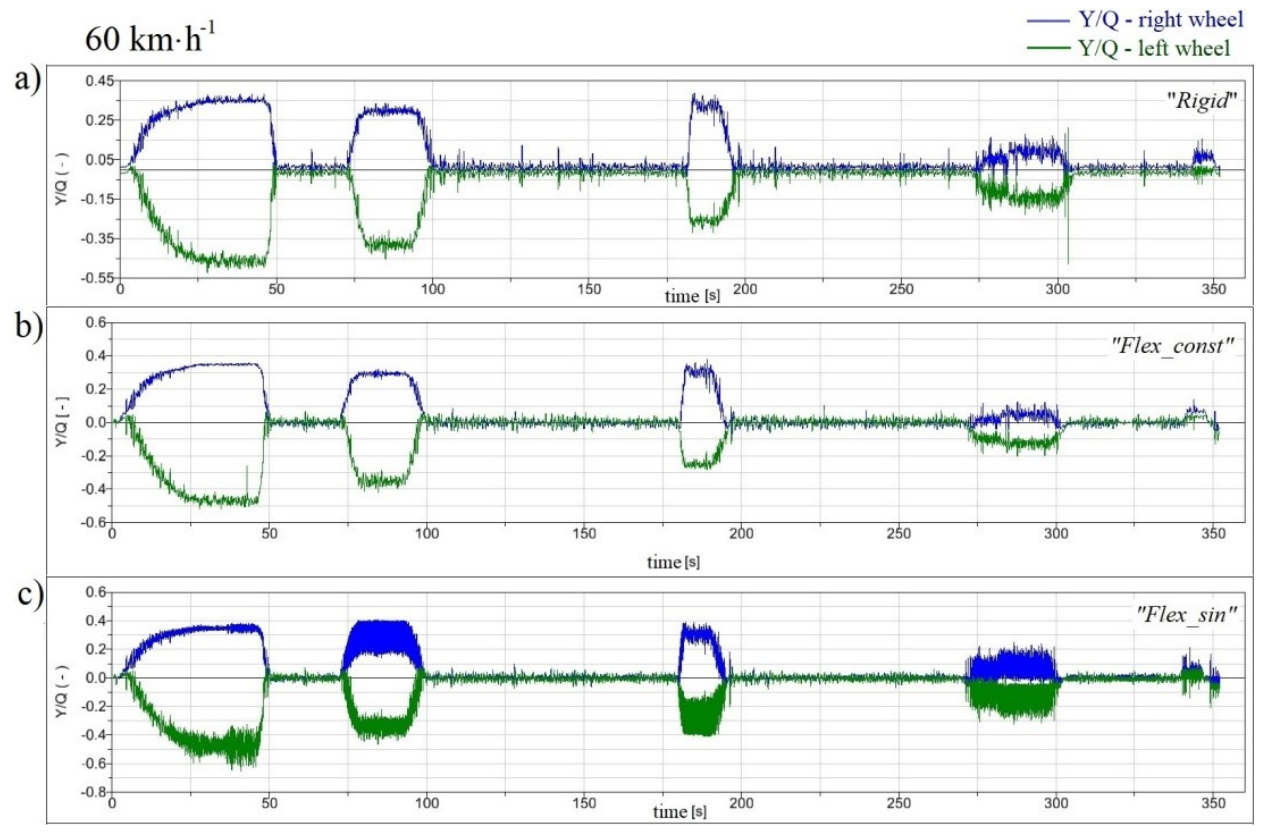

Fig. 6. Waveforms of the derailment quotient for the speed of $60 \mathrm{~km} \cdot \mathrm{h}^{-1}: \mathrm{a}$ ) "Rigid" track formulation, b) "Flex_const" track formulation, c) "Flex_sin" track formulation.

When evaluating the monitored waveforms of the derailment quotient for various track formulations we can observe, that using the flexible track model with constant stiffnessdamping characteristics ("Flex_const") partially results in damping the dynamic effects of the rail vehicle. From results of simulation computations reached for the flexible track formulation with variable values of stiffness-damping characteristics ("Flex_sin") we can see, the amplitudes of derailment quotient are significantly greater in comparison with the rigid track formulation ("Rigid"). It can be stated, that these greater amplitudes are due to varying parameters along the track, and the formulation used in the model does not sufficiently reflect the characteristics of the real track.

\section{Conclusion}

The main objective of the article was to analysed the influence of formulation of flexible railway track on output parameters. In our case we have found out, the extension of the railway vehicle multibody model by flexible track formulation has not influenced values of $N_{M V}$ indices significantly. However, process time for defined conditions has risen for the constant values of stiffness-damping characteristics approx. of 15-20\% and for variable values of stiffness-damping parameters even of 45-50\%. Therefore, the user has to decide, 
which approach for modelling and simulation of a railway vehicle running on a railway track will use.

This work was supported by the Cultural and Educational Grant Agency of the Ministry of Education of the Slovak Republic in the project No. KEGA 023ŽU-4/2020: Development of advanced virtual models for studying and investigation of transport means operation characteristics.

The work was supported by the Slovak Research and Development Agency of the Ministry of Education, science, Research and Sport of the Slovak Republic in Educational Grant Agency of the Ministry of Education of the Slovak Republic in the project No. VEGA 1/0558/18: Research of the interaction of a braked railway wheelset and track in simulated operational conditions of a vehicle running in a track on the test bench.

\section{References}

1. V. Hauser, O. Nozhenko, K. Kravchenko, M. Loulova, J. Gerlici, T. Lack, Procedia Engineering 192 (2017)

2. J. Gerlici, M. Gorbunov, K. Kravchenko, O. Prosvirova, T. Lack, MATEC Web of Conferences 157 (2018)

3. J. Gerlici, V. Sakhno, A. Yefymenko, V. Verbitskii, K. Kravchenko, K. Kravchenko, MATEC Web of Conferences 157 (2018)

4. J. Soukup, J. Skocilas, B. Skocilasova, Mechanical Systems and Signal Processing 89 (2017)

5. EN 12299:2009. Railway applications. Ride comfort for passengers. Measurement and evaluation (2009)

6. R. Melnik, B. Sowinski, VSDIA 2014, 14 (2014)

7. A. Chudzikiewicz, R. Melnik, VSDIA 2012, 13 (2012)

8. A. S. Leblebici, S. Turkay, MED 2019, 27 (2019)

9. J. Sadeghi, S. Rabiee, A. Khajehdezfuly, International Journal of Structural Stability and Dynamics 19, 6 (2019)

10. J. Harusinec, A. Suchanek, M. Loulova, P. Strazovec, MATEC Web of Conferences 157 (2018)

11. P. Stastniak, J. Harusinec, Komunikacie 15, 4 (2013)

12. P. Stastniak, Manufacturing Technology 15, 5 (2015)

13. J. Soukup, J. Skocilas, B. Skocilasova, L. Rychlikova, Journal of Applied Nonlinear Dynamics 3, 4 (2014)

14. L. Izvolt, J. Harusinec, M. Smalo, Communications - Scientific Letters of the University of Zilina 20, 3 (2018)

15. J. Gerlici, T. Lack, J. Harusinec, Communications - Scientific Letters of the University of Zilina 16, 3a (2014)

16. J. Harusinec, M. Manurova, A. Suchanek, Manufacturing Technology 16, 5 (2016)

17. J. Gerlici, T. Lack, Z. Ondrova, Komunikacie 9, 4 (2007)

18. T. Lack, J. Gerlici, Komunikacie 10, 3 (2008)

19. D. Madalina, D. I. Stanica, Materials Science Forum 957 (2019) 